education \& training

\title{
Better safe than sorry: a survey of safety awareness and safety provisions in the workplace among specialist registrars in the South West
}

\section{AIMS AND METHOD}

A questionnaire was sent to all general adult psychiatry specialist registrars (SpRs, $n=33$ ) on the largest rotation in the South West to survey their safety awareness and provision for safety in their workplace.

\author{
RESULTS \\ The response rate was $82 \%$. Most \\ SpRs had received training, but less \\ than half within the previous 2 years. \\ Only $44 \%$ had been given induction \\ to their job and only $37 \%$ reported \\ inclusion in local safety procedures. \\ More than half felt they had to \\ interview in unsuitable rooms and
}

sometimes felt vulnerable or fearful at work. No personal involvement in violent incidents during SpR training was reported.

\section{CLINICAL IMPLICATIONS}

Important gaps in workplace safety provision for SpRs persist and should be addressed.
In 1998 and 1999, the NHS Executive carried out a survey of sickness absence, accidents and violence in all National Health Service (NHS) Trusts in England, and found that there were approximately 65000 violent incidents against NHS Trust staff each year. The average number of incidents in mental health/learning disability trusts was over three times the average for all trusts, and the NHS Zero-Tolerance Zone Campaign was launched in response to these findings in October 1999 (Department of Health, 2000).

Violence in the workplace is of increasing concern to junior doctors in general and trainee psychiatrists in particular (Bhugra et al, 1990). Assaults on psychiatrists have been recognised as an important occupational hazard (O'Sullivan \& Meagher, 1998) and there is some evidence that violence on psychiatric wards might be increasing (Shah et al, 1991; Owen et al, 1998). The Collegiate Trainees' Committee has repeatedly addressed issues around trainees' safety and has issued a number of clear recommendations regarding safety training, induction courses, local policies and procedures, and safety standards for interview rooms (Cormac et al, 1999).

Issues of safety also rated highly on the improve-

ment 'wish list' for trainees in a survey of active problems and issues recently undertaken by the Collegiate Trainees' Committee (Wilson et al, 2000). However, a survey of safety awareness and provisions for safety in the workplace among junior psychiatrists in Wales revealed gaps in the provision of safety training and facilities (Chubb, 1997).

We therefore decided to survey specialist registrars' awareness of safety training and actual safety provisions within the largest psychiatric specialist registrar rotation scheme in the South West (the Avon \& Wiltshire Mental Health Partnership NHS Trust currently serves a population of ca. 1.6 million).

\begin{abstract}
Method
Based on recommendations made in recent reports by Royal College of Psychiatrists Working Parties and the Collegiate Trainees' Committee (Cormac et al, 1999; Royal College of Psychiatrists Working Party, 1998; 2000) and a similar survey among junior psychiatrists in Wales (Chubb, 1997), we designed an anonymous, confidential questionnaire to survey safety awareness and provision for safety. We sent it to all specialist registrars (SpRs) within the Avon \& Wiltshire Mental Health Partnership NHS Trust who had a National Training Number in general adult psychiatry $(n=33)$. This included SpRs in dual training in old age and general adult psychiatry, but excluded those training in the specialities of forensic, child \& adolescent or learning disability psychiatry. The questionnaire was sent out in August 2001, when most SpRs had been in their current post for about 10 months. To optimise the response rate, the questionnaire was sent out for a second time a few weeks later.

The questionnaire consisted of a series of statements, and respondents were asked to indicate the ones reflecting their own experiences or opinions. Each SpR could rate the safety profile of up to five interview rooms used by them at their present post by ticking which of a given list of desirable safety features (Cormac et al, 1999) were present in each room.
\end{abstract}

\section{Results}

Twenty-seven out of 33 questionnaires were completed and returned, giving an overall response rate of $82 \%$. We have summarised responses to each question in Table 1.

\section{The sample}

One of the 27 respondents did not complete the section on general characteristics. Eighteen $(67 \%)$ were male and only two $(7 \%)$ were flexible trainees. The median age was 
35 , and respondents had completed a median of 1.5 years in SpR training and 7 years in psychiatric training.

\section{Safety training}

Most ( $n=24 ; 89 \%$ ) of the respondents had participated in some form of safety training at some time during their training and almost all $(n=23 ; 85 \%)$ of those who had safety training reported to have received some practical training. Training had mostly been funded by the SpR's employer $(n=22)$. However, only five SpRs had been given two or more training sessions and over half of the respondents had received no safety training within the past 2 years $(n=15)$.

\section{Table 1. Summary of responses}

\begin{tabular}{|c|c|c|c|}
\hline Safety training & $n$ & $\begin{array}{l}\% \text { of total } \\
(n=27)\end{array}$ & $\begin{array}{l}\% \text { of SpRs with } \\
\text { training }(n=24)\end{array}$ \\
\hline $\begin{array}{l}\text { At any time during your psychiatric training so far (i.e. as } \mathrm{SHO} \text { or } \mathrm{SpR} \text { ), have you ever } \\
\text { participated in any safety training? }\end{array}$ & 24 & $89 \%$ & \\
\hline Any theoretical safety training? & 13 & $48 \%$ & $54 \%$ \\
\hline Any practical safety training (e.g. breakaway techniques)? & 23 & $85 \%$ & $96 \%$ \\
\hline Any other form of safety training? & 2 & $7 \%$ & $8 \%$ \\
\hline \multicolumn{4}{|l|}{ Who paid for your safety training? } \\
\hline My employer & 22 & $82 \%$ & $92 \%$ \\
\hline I had to pay for it myself & 0 & $0 \%$ & $0 \%$ \\
\hline It was funded in some other way & 2 & $7 \%$ & $8 \%$ \\
\hline \multicolumn{4}{|l|}{ Have you attended any further training sessions since then? } \\
\hline Yes, one further session & 4 & $15 \%$ & $17 \%$ \\
\hline Yes, several sessions & 1 & $4 \%$ & $4 \%$ \\
\hline \multicolumn{4}{|l|}{ How much time has passed since you last participated in any safety training? } \\
\hline$>24$ months & 15 & $55.6 \%$ & $63 \%$ \\
\hline Induction & $n$ & $\begin{array}{l}\% \text { of total } \\
(n=27)\end{array}$ & $\begin{array}{l}\% \text { of SpRs with } \\
\text { induction }(n=12)\end{array}$ \\
\hline In your present SpR post, did you have any induction at the beginning of your placement? & 12 & $44 \%$ & \\
\hline Tour of the site and relevant buildings & 7 & $26 \%$ & $59 \%$ \\
\hline Written information about relevant local safety policies & 5 & $17 \%$ & $42 \%$ \\
\hline Guidance about maintaining personal safety and privacy & 3 & $11 \%$ & $25 \%$ \\
\hline Any other written material regarding safety or management of violence & 3 & $11 \%$ & $25 \%$ \\
\hline Protected time for induction (e.g. first clinics cancelled) & 7 & $26 \%$ & $59 \%$ \\
\hline Teaching or training sessions & 4 & $15 \%$ & $33 \%$ \\
\hline Any other form of induction & 5 & $19 \%$ & $42 \%$ \\
\hline Local policies and procedures & $n$ & $\begin{array}{l}\% \text { of total } \\
(n=27)\end{array}$ & $\begin{array}{l}\% \text { of relevant } \\
\text { subgroup }(n=17)\end{array}$ \\
\hline $\begin{array}{l}\text { Are you aware of any local safety policies or procedures actually being in place in any of the } \\
\text { teams you work with (e.g. alarm systems, active monitoring of absence from community } \\
\text { base etc.)? }\end{array}$ & 17 & $63 \%$ & \\
\hline If your team has local safety procedures, have you been included into any of these? & 10 & $37 \%$ & $59 \%$ \\
\hline Have you ever been expected to make emergency assessments alone in the community? & 9 & $33 \%$ & \\
\hline Experience of violence or assault & $n$ & $\begin{array}{l}\% \text { of total } \\
(n=27)\end{array}$ & \\
\hline \multicolumn{4}{|l|}{ Do you ever feel vulnerable or fearful for your personal safety at work? } \\
\hline No, I don't & 10 & $37 \%$ & \\
\hline Yes, sometimes I do & 16 & $59 \%$ & \\
\hline Yes, I do most of the time & 1 & $4 \%$ & \\
\hline \multicolumn{4}{|l|}{ Have you ever been assaulted or been involved in a violent incident at work? } \\
\hline Yes, during present job & 0 & $0 \%$ & \\
\hline Yes, during previous psychiatric $S p R$ job & 0 & $0 \%$ & \\
\hline Yes, during previous psychiatric SHO job & 18 & $67 \%$ & \\
\hline Yes, during other jobs & 4 & $15 \%$ & \\
\hline No, never & 7 & $26 \%$ & \\
\hline
\end{tabular}

SHO, Senior House Officer; SpR, Specialist Registrar

Bold figures denote data of particular relevance. 
F

education \& training

\section{Induction}

Less than half of all SpRs completing the survey had received any form of induction to their present post ( $n=14 ; 44 \%)$. Only five of these had received written information about relevant local safety policies, three (11\%) had some guidance about maintaining personal safety and privacy, and three had some other written material regarding safety or management of violence. Seven $(26 \%)$ had time protected from clinical commitments during induction and the same number were given a tour of the main hospital or community site. Only four $(15 \%)$ received formal teaching or training sessions during their induction

\section{Local policies and procedures}

Seventeen of the respondents (63\%) reported to be aware of local safety policies or procedures, but only 10 $(37 \%)$ were actively included in procedures such as active monitoring of absence from community base. Nine SpRs (33\%) had been asked to do emergency assessments alone in the community.

\section{Safety of interview rooms}

More than half of all the respondents ( $n=15 ; 56 \%)$ felt that they had to interview patients in unsuitable rooms. Fifty-nine rooms were rated for the presence of safety features based on College recommendations (Cormac et $a l, 1999)$ and the results have been summarised in Table 2 .

\section{Experience of violence or assault}

Sixteen respondents $(60 \%)$ reported that they sometimes felt vulnerable or fearful for their personal safety at work. One SpR felt this was the case most of the time and $10(37 \%)$ never felt vulnerable.

None of the respondents had been assaulted during their present or previous SpR posts. Eighteen (67\%) had experienced assault or been involved in a violent incident during a previous psychiatric SHO post and four (15\%) during other previous posts. Seven SpRs $(26 \%)$ had never been assaulted or been personally involved in a violent incident.

\section{Conclusion}

This survey, with a high response rate of $82 \%$, provides representative and valuable information about safety awareness and actual safety provisions for SpRs in the largest Mental Health Trust in the South West region of the UK.

There are some encouraging findings, especially the high proportion of SpRs (89\%) who had participated in some form of safety training. However, less than half of all respondents had received any safety training within the past 2 years, indicating problems regarding the necessary continuity of such training. Less than half of the respondents had been given a period of formal induction at the beginning of their post and, even more worryingly, only $37 \%$ were aware of having been actively included in
Table 2. Safety of interview room

\begin{tabular}{|c|c|c|}
\hline Safety of interview rooms & Yes $(n=59)$ & $\%$ \\
\hline $\begin{array}{l}\text { Is the room situated close to main staff } \\
\text { areas, i.e. not isolated? }\end{array}$ & 45 & $77 \%$ \\
\hline $\begin{array}{l}\text { Does the room have a readily- } \\
\text { accessible panic button? }\end{array}$ & 23 & $40 \%$ \\
\hline $\begin{array}{l}\text { If there is a panic button, are you } \\
\text { aware of any explicit policies, which } \\
\text { tell staff how to respond when an } \\
\text { alarm is raised? }\end{array}$ & 6 & $10 \%$ \\
\hline Does the room have unimpeded exit? & 33 & $56 \%$ \\
\hline Does the exit door open outward? & 8 & $14 \%$ \\
\hline $\begin{array}{l}\text { Can the door be opened without a key } \\
\text { to exit? }\end{array}$ & 54 & $92 \%$ \\
\hline $\begin{array}{l}\text { Is the room suitably furnished and free } \\
\text { of clutter? }\end{array}$ & 40 & $68 \%$ \\
\hline $\begin{array}{l}\text { Does the room have an internal } \\
\text { inspection window to permit } \\
\text { viewing when the room is occupied? }\end{array}$ & 15 & $25 \%$ \\
\hline
\end{tabular}

(Surveyed safety features based on Royal College recommendations (Cormac et al, 1999).)

local safety policies and procedures. Clear induction procedures could help to improve this situation by introducing and including SpRs to local safety arrangements. Interview room safety was another area that suggested the persistence of significant gaps, disregarding official College recommendations (Cormac et al, 1999): again, more than half of all the respondents reported that they had to interview patients in unsuitable rooms. Out of 59 rated interview rooms, only 23 had readilyaccessible panic buttons and for only six out of these 23 rooms were SpRs aware of any explicit policies on how to react if an alarm was raised. Lillywhite et al (1995) had surveyed interview room safety in parts of the area covered currently by the Avon \& Wiltshire Mental Health Partnership NHS Trust, and made recommendations for improvements and regular audits. Our survey suggests that there is still scope for further work in this area.

We were encouraged to find that despite the abovementioned gaps and problems with safety provisions, none of the SpRs surveyed reported any personal involvement in an assault or violent incident during any of their SpR jobs. However, two-thirds reported such personal involvement during previous psychiatric $\mathrm{SHO}$ jobs. This unexpected finding clearly underlines the importance of monitoring and raising safety standards for all trainees. The majority of SpRs (60\%) felt at times vulnerable or fearful for their personal safety at work. Improvements in areas such as regular provision of safety training, formal induction and inclusion in safety procedures, as well as further improvements in interview room safety, could help to increase their overall job safety and satisfaction.

This audit was carried out prior to a General and Old Age Psychiatry Specialist Advisory Sub-Committee accreditation visit by the Royal College of Psychiatrists, and we have presented our findings to the SpR Programme Director and the Training Committee of Avon 
\& Wiltshire Mental Health Partnership NHS Trust. Although we did not include SpRs from other psychiatric specialities (e.g. forensic, child \& adolescent or learning disability) nor SHOs in this audit, we recommend monitoring the effectiveness of any potential improvements through further regular surveys of all psychiatric trainees.

\section{Acknowledgement}

We would like to thank SpR Programme Director Dr Brian Robinson for his support during this study.

\section{Declaration of interest}

None.

\section{References}

BHUGRA, D., SMITH, J. \& JUNAID, O (1990) Doctors' safety: Who cares? BMJ, 301, 43 .

CHUBB, H. (1997) Safety awareness among junior psychiatrists and provisions for their safety in the
DEPARTMENT OF HEALTH (2000) NHS zero tolerance zone. http:// www.nhs.uk/zerotolerance/mental/ index.htm.

LILLYWHITE, A., MORGAN, N. \& WALTER, E. (1995) Reducing the risk of violence to junior psychiatrists. Psychiatric Bulletin, 19 24-27.

O'SULLIVAN, M. \& MEAGHER, D.

(1998) Assaults on psychiatrists a three year retrospective study. Irish Journal of Psychological Medicine, 15 54-57.

OWEN, C., TARANTELLO, C., JONES, M. et al (1998) Violence and aggression in psychiatric units. Psychiatric Services, 49, 1452-1457.

ROYAL COLLEGE OF PSYCHIATRISTS WORKING PARTY (1998) Not Just Bricks and Mortar. London: Royal College of Psychiatrists.

- (2000) Good Medical Practice in the Psychiatric Care of Potentially Violent Patients in the Community. London: Royal College of Psychiatrists.

SHAH A. K., FINEBERG, N. A. \& JAMES, D. V. (1991) Violence among psychiatric inpatients. Acta Psychiatrica Scandinavica, 84, 305-309.

WILSON, R., CORBY, C. L., ATKINS, M. et al (2000) Trainee views on active problems and issues in UK psychiatry: CollegiateTrainees' Committee survey of three UK training regions. Psychiatric Bulletin, 24, 336-338.

*Attila Sipos Lecturer in Psychiatry, Division of Psychiatry, University of Bristol, Cotham House, Cotham Hill, Bristol BS6 6JL e-mail: Attila.Sipos@bristol.ac.uk, Robin Balmer Specialist Registrar in General Adult Psychiatry, Theresa Tattan Senior Registrar in Forensic Psychiatry 